\title{
Variation of the Thermal Properties of a
}

\section{Polyurethane-Polyethylene Composite}

\author{
Jacques Cousteau da Silva Borges $^{1 *}$, Manoel Leonel de Oliveira Neto ${ }^{1}$ and George Santos Marinho ${ }^{2}$ \\ 1. Physics Laboratory, Instituto Federal de Educ. Ciência e Tecnologia do Rio Grande do Norte-IFRN., Natal-RN 59015-000, Brazil \\ 2. Laboratory of Heat Transfer, Universidade Federal do Rio Grande do Norte-UFRN., Natal-RN 59078-970, Brazil
}

\begin{abstract}
This paper discusses the behavior of the thermal properties of polymer composites made of a natural polyurethane matrix and loads of different waste of HDPE (High density polyethylene) industry. This polymer is partially crystalline, having amorphous phases and crystalline phases, HDPE type is harder and tougher than other polyethylenes, having a wide range of applications that depend almost exclusively on the processes for obtaining final products. After the process, waste from the manufacture of these products are discarded daily as they are not found effective ways to use this material. In this study we seek to use this "factory floor" to act as filler in a polyurethane matrix derived from the castor oil, which is a natural biodegradable. The residue loads were separated according to the process that originated in this way have been the A residue from the process of cork and the B residue derived from the extrusion process. Specimens in mass proportions of $10 \%, 20 \%$ and $30 \%$ polyethylene both loads were prepared and their thermal properties were mediated, these being the thermal conductivity (k), specific heat (c) and thermal diffusivity $(\alpha)$. By adding such fillers to castor polyurethane matrix, different behaviors were observed, because of the residue contributed to a reduction in conductivity and specific heat of the composite material. Since the residue B on average $47 \%$ higher than residue, caused an increase in these same properties as before the spaces filled with air only into the polyurethane are now filled with polyethylene grains. We can see then that the particle size of the HDPE waste has a direct influence on the improvement of the thermal properties of the analyzed composite material.
\end{abstract}

Key words: Thermal properties, polyethylene, polyurethane, reutilization.

\section{Introduction}

In industrial production waste generation is inevitable, from the product manufacturing processes. That is why every day, searching for the possibility of minimizing the amount of waste material or a form of recycling these products, since in most cases it is not possible to return to the residue certain stages of the production chain. This is evident in industrial chemical, which is a series of chemical transformations of the raw material until it reaches the final product.

In a plastics packaging industry, the scenario is no different. This industry used HDPE (High density polyethylene), being chemically inert, is used in

*Corresponding author: Jacques Cousteau da Silva Borges, M. Sc., research fields: instrumentation, control and properties of new materials. E-mail: cousteau.borges@ifrn.edu.br. making medicine bottles, bottles for detergents and other products. Such items are obtained through a process known as "blowing", that forms the structure of the containers. Similarly, the extrusion process prepares from the same HDPE plastic bags, lightness and strength that bind to transport groceries and many other items.

However, in both cases there is the formation of solid waste. Such waste is minimized to the maximum, but it is not possible to eliminate it. In the evening, have always a certain amount of waste product in the final processes, called "shop floor". This work will employ this material in the composite composition for thermal insulation, aiming to give a final destination for this residue after removal of the factory.

To further minimize the environmental impact, we opted for a natural polyurethane matrix, derived from castor oil, which proved to be a good thermal insulator, 
with comparable efficiency to more insulating clerks, such as glass wool and rock wool.

Thus, the residual materials were separated from the source process (blast or extrusion) and incorporated the natural polyurethane matrix in different proportions. Following a discussion is made about the behavior of the thermal properties of these polymer composites.

The paper is organized as follows: section 2 presents the materials used. Section 3 details the production methodology of the test bodies and the measuring system of the thermal properties. Section 4 presents the results and discussion, and finally, section 5 provides conclusions.

\section{Materials}

\subsection{Polyurethane Castor Oil}

Resins PU (Polyurethane) were developed and patented by chemist Otto Bayer in 1937, although the reactions of formation of urethanes were postponed by WURTZ well before, in 1849. Its marketing began still in the $30 \mathrm{~s}$ In the $40 \mathrm{~s}$, in Germany and England elastomers PU originated. However, during the period of World War II the development of PU was discontinued, but since 1946 its market has shown tremendous growth $[1,2]$.

The polyurethane resins can derive both the oil as vegetable oils, these are called "biomonomers". These oils may be derived from plants such as maize, sunflower, soybean, canola, carob, olive, peanut and castor oil as well. Although the most used biomonomer polyurethane is derived from castor oil, it is possible to find scientific work with the most different raw materials for obtaining a natural polyurethane.

The development of polyurethanes derived from castor oil originated in the early work on polyurethanes, in the decade of 40 . The Castor oil is obtained from plant seed "ricinus communis", very abundant in Brazil, as this is typical of regions tropical and subtropical. The oil is a viscous liquid. Obtained by compression of the seeds or by solvent extraction [3].

Castor oil is one of the few natural sources approaching a pure compound, since around $90 \%$ of the fatty acid present in the composition of castor oil triglyceride is ricinoleic acid. The big difference of ricinoleic acid in relation to the other fatty acids present in nature is the presence in their molecular structure of hydroxyl group at carbon 12, which makes the triglyceride of ricinoleic acid a natural polyol $[2,3]$.

Thus, it is possible to use the polyurethane derived from natural sources without many difficulties. The development of eco-friendly materials and the best way adequacy of processes has been a need to minimize the environmental problems in the world. The possibility of being able to work with a product from renewable nature encouraged several studies and research with this type of material [4]. Many new materials have been developed, taking this expanding resin as the matrix for possible mechanical applications as well as in insulation systems. Previous work has highlighted the effectiveness of castor polyurethane thermal insulation systems, showing that the biodegradable insulator may be used as insulation with efficiency comparable to conventional thermal insulation [5-7].

\subsection{Polyethylene}

PE (Polyethylene) presents one of the simplest structures of all polymers. It is a thermoplastic, partially crystalline, flexible, whose properties are strongly influenced by the relative amounts of amorphous and crystalline phases. This polymer is inert against most of the common chemicals because of its nature, its high molecular weight and structure.

Although the chemical composition remain constant, the polyethylene may differ in their physical and chemical properties due to polymerization conditions, density and others, giving rise to various types of polyethylene, the most striking difference being that 
regulated the type degree of branching [6-8]. The various types of polyethylene structure depend on the method by which the polymer is obtained. The three most important commercially are LDPE (Low density polyethylene), LLDPE (Linear low density polyethylene) and HDPE (High density polyethylene).

The latter is a research subject of this work. HDPE has a higher proportion of crystalline phase to the amorphous phase being harder and tougher than other polyethylene's, having a wide range of applications that depend almost exclusively on the processes for obtaining final products. For example, the blasting process is employed in the manufacture of bottles for drugs, detergents and other packaging. Since the extrusion producing plastic bags, such as trash and "supermarkets".

\section{Methodology}

After the process, waste from the manufacture of these products are discarded daily as they are not found effective ways to use this material. In this study we sought to use this "shop floor" to act as filler in a polyurethane matrix derived from the castor oil, which is a natural, biodegradable. The residue loads were separated according to the process that originated in this way has the A (Fig. 1a) residue from the process of cork and the residue B (Fig. 1b) derived from the extrusion process.

These residues were taken up in mass proportions of $10 \%, 20 \%$ and $30 \%$ both polyethylene fillers, castor to compose a polyurethane matrix with the intention of making the specimens for measurement of thermal properties.

The matrix consists of an expanding resin, composed of two distinct components (Fig. 2): the component $\mathrm{A}$ and $\mathrm{B}$. Component $\mathrm{A}$ is a prepolymer consisting of ricinoleic acid and an isocyanate component $\mathrm{B}$.

The reaction occured under the mass ratio of 1:2. While reacting, the isocyanate was binded to the hydroxyl groups of component $\mathrm{A}$, releasing $\mathrm{CO}_{2}$ in the process. This gas released promotes the expansion of resin, which increased its volume twenty times relative to the initial volume of the mixture of the components. Thus, the composite mixture were conducted using the data shown in Table 1, keeping constant the final mass of the material:

The tests for thermal properties of materials (conductivity, diffusivity and heat capacity) were performed at the Laboratory of GGEMMA-Research Group on marine geology and environmental Monitoring UFRN (Universidade Federal do Rio Grande do Norte) through the Quick-line equipment 30 (Prev Thermal Properties Corp).

Specific were prepared test pieces for measuring these properties, of cylindrical shape $(\mathrm{h}=18 \mathrm{~cm}$, $\mathrm{d}=8 \mathrm{~cm}$ ), which was inserted into a probe in the form of a needle (Fig. 3). The measurements of each property were repeated three times.

\section{Results}

Table 2 shows the results CRS (composite cork
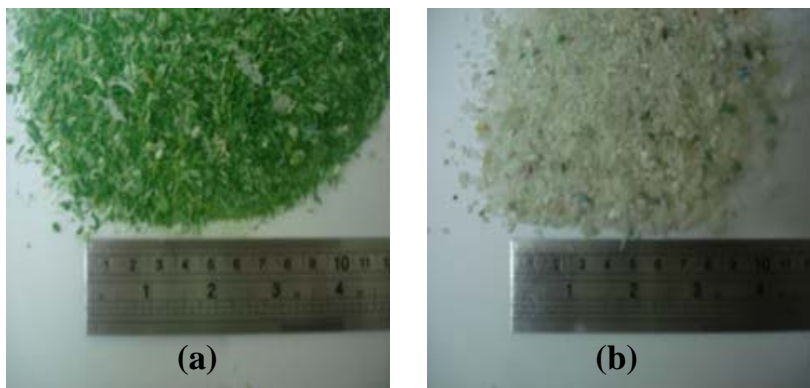

Fig. 1 Polyethylene waste from industrial processes (a) cork and (b) extruding.

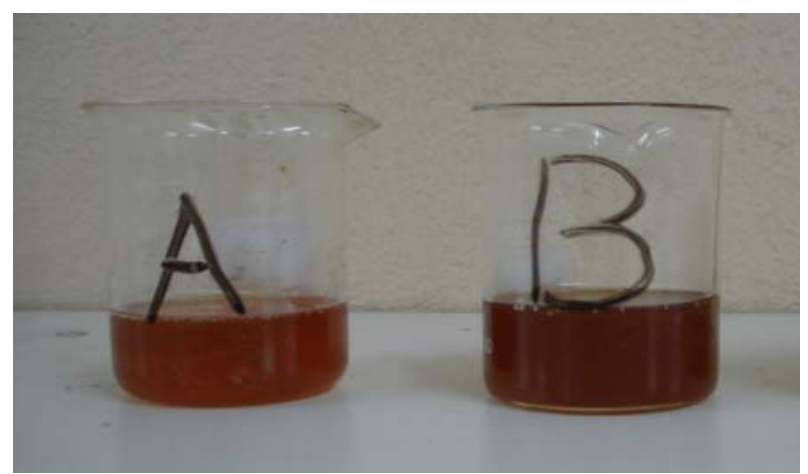

Fig. 2 Prepolymer (A) and isocyanate (B). 
Table 1 Values of the masses of the composite components.

\begin{tabular}{lllll}
\hline $\begin{array}{l}\text { Material } \\
(\%)\end{array}$ & $\begin{array}{l}\text { Comp. A } \\
(\mathrm{g})\end{array}$ & $\begin{array}{l}\text { Comp. B } \\
(\mathrm{g})\end{array}$ & $\begin{array}{l}\text { Polyethylene } \\
(\mathrm{g})\end{array}$ & $\begin{array}{l}\text { Total } \\
\text { mass }(\mathrm{g})\end{array}$ \\
\hline Matrix & 30.0 & 60.8 & - & 90.0 \\
10 & 27.0 & 54.0 & 9.0 & 90.0 \\
15 & 25.5 & 51.0 & 13.5 & 90.0 \\
20 & 24.0 & 48.0 & 18.0 & 90.0 \\
\hline
\end{tabular}

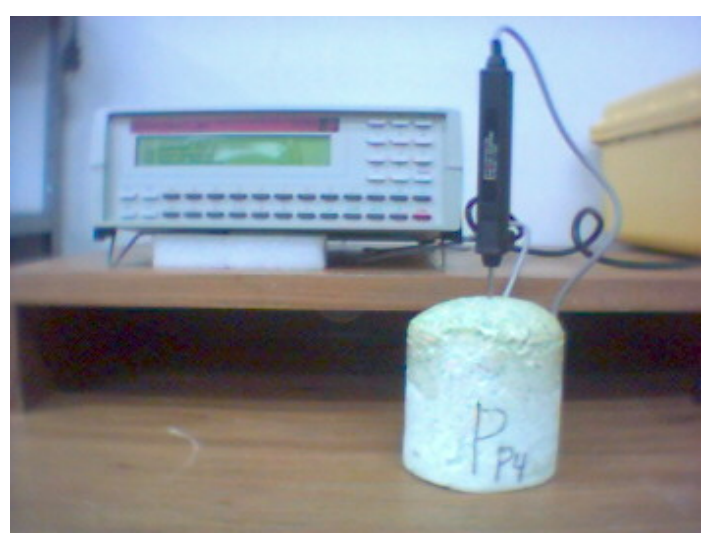

Fig. 3 Equipment for measuring thermal properties.

Table 2 Results obtained in measurements of thermal properties.

\begin{tabular}{llllll}
\hline \multicolumn{2}{l}{ Material $(\%)$} & $\begin{array}{l}\mathrm{k} \\
\left(\mathrm{W} \cdot \mathrm{m}^{-1} \cdot \mathrm{k}^{-1}\right)\end{array}$ & $\begin{array}{l}\mathrm{c} \\
\left(\mathrm{J} \cdot \mathrm{kg}^{-1} \cdot \mathrm{k}^{-1}\right)\end{array}$ & $\begin{array}{l}\alpha \\
10^{6}\left(\mathrm{~m}^{2} \cdot \mathrm{s}^{-1}\right)\end{array}$ & $\begin{array}{l}\rho \\
\left(\mathrm{kg} \cdot \mathrm{m}^{-3}\right)\end{array}$ \\
\hline \multirow{3}{*}{ CRS } & 30 & 0.3380 & 1387.54 & 0.311 & 78.34 \\
& 20 & 0.3650 & 1448.23 & 0.318 & 79.20 \\
& 10 & 0.0385 & 1447.05 & 0.313 & 85.00 \\
\hline \multirow{2}{*}{ Matrix } & 0 & 0.0406 & 1400.00 & 0.363 & 80.00 \\
\hline \multirow{4}{*}{ CLP } & 10 & 0.0408 & 1352.12 & 0.334 & 90.45 \\
& 20 & 0.0412 & 1325.37 & 0.307 & 101.33 \\
& 30 & 00422 & 1481.19 & 0.274 & 103.97 \\
\hline
\end{tabular}

residue) and CLP (residual composite extrusion).

In analyzing the results presented in Table 2 show that the addition of such fillers castor polyurethane matrix promotes different behaviors. The specimens made with the CRS residue showed a reduction in the thermal conductivity and specific heat of the composite, while those made with CRS residue, particle size $47 \%$ higher on average showed an increase in these same properties. It is believed that the change in these properties due to the occupation of a portion of the space before filled with air only in polyurethane, polyethylene by grains. This finding can be supported by the density values obtained for the said composite, which noted that the lower density samples were presented the lowest thermal properties.

\section{Conclusions}

Although the present paper represents the initial phase of the research, the results suggest that the behavior of the thermal properties of the composite evidence its application in thermal insulation. The differences presented show the influence of particle size of the waste analyzed the thermal properties of composites, may suit the application of the particulate material. In addition, this research also opens another recycling option bags and polyethylene bottles after your domestic use, contributing to the preservation of a sustainable environment.

\section{References}

[1] Silva, R. V. 2003. "Resin composite polyurethane derived from castor oil and vegetable fibers." Thesis (Inter Area in Materials Science and Engineering). USP.

[2] Silvestre F. G. D. 2001. "Mechanical Behavior Polyurethane Castor OiSl Derivative Reinforced by Carbon Fiber: Contribution to the Hip Implant Rods Project." Thesis (Escola de Engenharia de São Carlos), USP.

[3] LiMdeBERGER, H. J. et al. 2013. "Polyurethanes Castor Oil-Based." Revista Jovens Pesquisadores 3 (3): 6-16.

[4] Ventura, F. C., Ramos, B. P. F. and Pereira, M. A. R. 2014. "Verification of Applicability of the Polyurethane Adhesive Based on Castor Oil in the Manufacture of Glued Laminated Bamboo." Journal of Chemistry and Chemical Engineering 8: 898-905.

[5] Borges, J. C., Oliveira, N. M. L. and Marinho, G. S. 2014. "Measurement Module for Young for Thermal Insulation Composite Polymeric." Journal of Mechanics Engineering and Automation 12: 969-74.

[6] Marinho, G. S.and Oliveira Neto, M. L. 2012. "The Experience of Setting up a Heat Transfer Laboratory." Mens Agitat, v. 7: 39-51.

[7] Rahn, M. A. S. and Marinho, G. S. 2011. "Thermal Conductivity Coefficient of Variation of a Composite Matrix Pur Nop with Functional Load Clay Mineral." Química dos Materiais 1: 1.

[8] Oliveira, I. T. D. 2007. "Mechanical Evaluation of HDPE (High Density Polyethylene) Composites Vermiculita." Dissertation (Master in Polymer Science and Technology), UFRJ. 